\title{
O JOGO DA HISTORICIDADE ${ }^{1}$
}

Rainri Back ${ }^{2}$

Resumo: Nosso propósito geral consiste em mostrar que o jogo é o fenômeno estruturador de toda a historicidade da existência humana. Mas, para realizá-lo, são necessários dois passos preliminares. Primeiro, nos precaver de alguns problemas provenientes das interpretações de Dilthey e de Heidegger a respeito da historicidade. Segundo, nos livrar da interpretação determinista que Gadamer confere ao fenômeno do jogo. Por fim, mostraremos que a transformação do que a tradição nos lega também é uma tarefa do jogo da historicidade.

Palavras-chave: Jogo, Historicidade, Transformação.

\begin{abstract}
My aim is to show that the game is a phenomenon that structures historicity of human existence as a whole. In order to accomplish it, two preliminary steps are required. First, we need to prevent some problems coming out of the interpretation of historicity put forward by Dilthey and Heidegger. Second, we need to rid ourselves of a deterministic interpretation of game such as that offered by Gadamer. I shall then proceed to show that the transformation of what tradition provides us is also a task within the game of historicity.
\end{abstract}

Keywords: Game, Historicity, Transformation.

\footnotetext{
${ }^{1}$ O presente artigo é uma versão revisada do capítulo "O Jogo da Historicidade", que compôs a dissertação Nos Rastros da Situação Hermenêutica, defendida no Programa de Pós-Graduação em Filosofia da Universidade de Brasília - UnB, no início de 2010, sob a orientação do Prof.Dr. Gerson Brea, e que contou o subsídio da CAPES.

${ }^{2}$ Doutorado em Filosofia pela Universidade Estadual do Rio de Janeiro - UERJ, sob orientação do prof. Dr. Marco Antonio Casanova. Contato com o autor: rainri_bach@yahoo.com.br
} 


\section{CONSIDERAÇÕES PRELIMINARES.}

Essencialmente, a linguagem surge e se mantém vigente a partir de relações interhumanas. Não se trata de um traço contingente do qual a linguagem pudesse prescindir. Ninguém pode nem instituir uma linguagem contando apenas consigo mesmo nem se considerar o único responsável por aquilo que diz. As palavras somente significam o que significam em virtude de uma longa história cuja narrativa não para de fluir e de passar adiante um legado.

Então estamos à mercê do fluxo da história? Ora, a tradição não nos acomete a partir de fora, como se fosse algo com o qual nada tivéssemos em comum. Cada um é em si mesmo história; cada um responde pela influência que a história exerce sobre si, na medida em que a leva adiante com sua existência. Portanto, existir historicamente sempre nos impõe uma tarefa: apropriar-nos daquilo que a tradição nos legou por meio das palavras da linguagem.

Mas qual seria o teor preciso dessa tarefa? Essa apropriação visaria depurar as palavras a ponto de fazê-las revelar, enfim, aquilo em virtude do qual a própria linguagem veio-a-ser linguagem? Aquilo que, para se tornar manifesto, sempre requereu a escuta atenta de um "genuíno mensageiro"? Aquilo que, todavia, se manteve oculto, porque durante um longo período reinou a falta de tato para atender aos apelos silenciosos de um fenômeno assim tão singelo?

Se assim fosse, então a linguagem deixaria de se realizar de modo inter-humano. Primeiro, seria necessário suspender a influência dessa falta de tato de todos aqueles por intermédio dos quais ainda hoje nos fala essa tradição. Só quando não houvesse a interferência de ninguém, seria possível ver aquilo a cujos apelos todos respondem sem o saber. Assim, seria necessário submeter a linguagem ao empreendimento absolutamente particular de alguém.

Não é assim que pretendemos nos apropriar aqui dos conceitos. Só almejamos contribuir tão bem quanto possível no debate com a tradição precedente e em vigor.

Cabe à linguagem revelar, mostrar coisas. Entretanto, essa revelação jamais chega a ser inequívoca. Embora não se esgote no que é possível dizer a seu respeito, as coisas que se mostram na linguagem também não são meras "representações" subjetivas, como se houvesse um fosso entre elas e o pensamento. Não. O que consideramos verdade é exatamente a 
experiência de um diálogo infindável de uns com os outros, que juntos fazemos valer uma tradição, a respeito das próprias coisas; infindável, porque as coisas sempre podem se mostrar a partir de si mesmas de uma maneira diversa daquela em que vinham se mostrando até então.

Isso não é um problema. Exatamente aí o pensamento descobre a sua maior riqueza. Ele jamais se absolutiza na perspectiva de alguém particular, mas sempre se difunde em um intenso e ininterrupto debate onde cada um pode tomar a palavra para, depois, passá-la a outro. Essa situação não descamba em uma balbúrdia desenfreada onde cada um fala o que dita o seu próprio capricho. O que cada um pode mostrar diversamente se faz valer por si mesmo e passa pelo crivo dos outros. Em suma, as coisas não estão a mercê do que queremos dizer sobre elas.

É sob esse panorama que as considerações seguintes devem ser interpretadas.

Feitas tais advertências, passemos ao tema propriamente. Já que pretendemos nos apropriar dos conceitos em apreço na nossa investigação, primeiro, devemos nos perguntar: o que se entende em geral por historicidade? Essa palavra geralmente é empregada para afirmar a existência efetiva, real, de algo passado. Essa palavra também é usada para ressaltar a importância de um acontecimento passado ou contemporâneo. Em ambos os casos, a historicidade aparece sob a orientação da historiografia, que pretende conferir objetividade e valor a acontecimentos que, todavia, já não se encontram mais presentes aqui e agora diante de nós.

Mas 'historicidade' também designa o modo de ser da história. Esse significado envolve e fundamenta os dois primeiros, já que visa aquilo que ambos apenas pressupõem. Ora, se uma investigação filosófica deve visar os fundamentos, devemos nos deter nesse último significado. Mas, como já dissemos, as palavras da linguagem são resultado de um longo debate em torno daquilo mesmo que elas podem nos mostrar. E se pretendemos entrar nesse debate, devemos nos aproximar dos interlocutores pelos quais nos chegam as palavras das quais nos valemos. Essa aproximação deve buscar o horizonte de pressuposições desde onde eles falam conosco.

\section{HISTORICIDADE.}

2.1. A interpretação epistemológica de Dilthey. 
Alguns filósofos conquistaram um reconhecimento mais amplo e duradouro no debate sobre aquilo que concerne à historicidade. Se não o primeiro, Wilhelm Dilthey é ao menos um dos mais importantes desses filósofos. Invariavelmente, todo debate relacionado à história passa a considerar aquilo que ele buscou estabelecer a respeito disso. Decerto, devemos muito a Dilthey o que hoje compreendemos por historicidade. Mas isso não o isenta de alguns problemas que se devem, sobretudo, ao horizonte epistemológico de onde ele parte. Portanto, devemos não só retornar a Dilthey como ainda denunciar alguns dos seus limites.

Em geral, as investigações de Dilthey se tornaram conhecidas pelo esforço para demonstrar que as "ciências do espírito" (Geisteswissenschaften), então emergentes, são ciência em sentido genuíno e também muito particular. Já que as ciências da natureza se tornaram padrão de conhecimento, tudo se passava como se o mundo fosse constituído somente por relações de causa e efeito puramente físicas. Contra essa tendência, Dilthey passa a defender a necessidade de uma "crítica da razão histórica" (Id., 1978:304), pois no mundo há outros fenômenos que também podem ser conhecidos e que, todavia, não se baseiam em relações meramente físicas. Quando se trata de economia, política, religião etc., é necessário compreender relações humanas cujo sentido se funda em vivências, em impulsos vitais, que originariamente estão entretecidos uns nos outros.

Na seguinte passagem, notemos, sobretudo, o que Dilthey denomina "referências vitais" e a diferença disso em relação à "conexão causal":

Não capto nela [na vida] outros homens e coisas apenas como realidades que se encontram comigo e entre si numa conexão causal: referências vitais partem de mim para todos os lados, relaciono-me com homens e coisas, tomo posição perante eles, satisfaço as suas exigências a meu respeito e deles espero algo. Alguns tornam-me feliz, ampliam a minha existência, acrescentam a minha força; outros exercem sobre mim uma pressão e restringem-me. (DILTHEY, 1992:111-112).

Notem: tomar posição perante alguém, satisfazer as exigências dos outros, esperar algo deles, fortalecer-se ou acuar-se devido à ação alheia - nada disso pode ser reduzido a meras relações mecânicas de causa e efeito! Entretanto, Dilthey ainda se deixa levar pelas orientações epistemológicas das ciências naturais, já que submete a vida humana à seguinte pergunta: como é possível conhecê-la de maneira necessária e universal? Enquanto objeto científico, a vida deve conter leis cognitivamente necessárias e universais que, embora não possam ser conhecidas pelos métodos das ciências naturais, devem sê-lo por meio de 
outros métodos. Só assim, segundo Dilthey, as ciências do espírito podem ter um estatuto genuinamente científico.

Contudo, as ciências do espírito revelam um nexo essencial com a história que parece ser um obstáculo intransponível para satisfazer esse critério de cientificidade. Para Dilthey, cada indivíduo é um "ponto onde se cruzam sistemas de relações" e onde se realizam "bens de comunidade" (DILTHEY, 1978:178). As referências vitais que cada indivíduo mantém consigo, com os outros e com as coisas arredor, formam em conjunto um sistema cultural. Ele oferece estabilidade aos indivíduos cuja cooperação mútua, em compensação, mantém esse sistema em vigor. Trata-se de uma reformulação curiosa do velho princípio da reciprocidade entre partes e todo, oriundo da hermenêutica (Cf. SCHLEIERMACHER, 2000: $46 s)$.

Enfim, a vida se concretiza em tais comunidades de indivíduos e nas obras aí produzidas que são, como diz Dilthey, "uma realização do espírito no mundo sensível" (DILTHEY, 1978: 170). Essa objetivação da vida revela duas características fundamentais. Primeiro: qualquer manifestação da vida em um indivíduo singular somente pode ser compreendida em referência à comunidade da qual ele faz parte, conforme reza aquele já mencionado princípio da reciprocidade entre partes e todo. Há uma passagem em que Dilthey nos diz isso muito claramente:

Toda manifestação de vida singular representa, no reino desse espírito objetivo, algo comum. Cada palavra, cada frase, cada gesto ou forma de cortesia, cada obra de arte e cada fato histórico, são inteligíveis porque há uma "comunidade" que une o que neles se manifesta ou se exterioriza com o que o compreende; o indivíduo vive, pensa e trabalha sempre em uma esfera de "comunidade" e só em tal esfera compreende. Todo o que é compreendido leva consigo a marca de familiaridade, de ser conhecido em razão dessa "comunidade". Vivemos nessa atmosfera que nos rodeia por todos os lados. Encontramo-nos imersos nela. (DILTHEY, 1978:170).

A segunda característica da objetivação da vida é a diversidade de ordens sob as quais os indivíduos podem formar comunidades. Entretanto, nos perguntamos aqui: qual a origem da possibilidade de as comunidades diferirem entre si? Dilthey não nos oferece claramente uma resposta, embora possamos depreendê-la daquilo que ele mesmo nos legou em suas obras. Além disso, devemos suprir outra deficiência: mostrar a correlação entre a primeira e a segunda característica da objetivação da vida e fazer ver em que medida uma 
esclarece a outra. Trata-se de uma questão sumamente importante para os fins particulares da nossa investigação.

Uma comunidade não só proporciona consistência e estabilidade a cada indivíduo como ainda lhe impõe várias restrições sob a forma de dogmas e preconceitos tradicionais (Cf. DILTHEY, 1992:55). Mas o indivíduo também alimenta em si um impulso em favor da satisfação e do alargamento de si mesmo, de sorte que sempre pode confrontar aquilo que o restringe. Logo, há um âmbito na vida em comum onde vigoram a "originalidade e profundidade" pessoais - que não podem ser reduzidos ao comum vigente na comunidade, ao que pode ser inteligível. Trata-se de uma herança de Schleiermacher presente no pensamento de Dilthey: individuum est ineffabile (SCHLEIERMACHER. apud DILTHEY, 1978: 335).

Podemos ver assim uma constante tensão no interior daquela relação recíproca entre partes e todo, entre indivíduos e sistema cultural. Somente porque os indivíduos, devido à condição mesma de indivíduos, não podem ser reduzidos ao que uma comunidade em si mesma representa, pode haver aqui e ali configurações distintas de sistemas culturais. Embora Dilthey não diga nada a respeito, podemos depreender da diversidade uma terceira característica da objetivação da vida: a possibilidade de uma mesma comunidade se transformar ao longo do tempo. Isso só é possível porque a comunidade sempre passa pela mediação do que cada indivíduo enquanto indivíduo pode fazer com aquilo que ele compartilha em comum com os outros. ${ }^{3}$

Não é exatamente o que Dilthey nos diz, mas é aquilo que podemos fazer ver e de que podemos nos apropriar a partir do que ele nos diz. Ser histórico, portanto, consiste em trazer consigo tais características: ser fruto de algo comum e estável que, todavia, está sujeito a transformações. Logo, as ciências do espírito, para fazer jus ao título de ciência, precisam elaborar um conhecimento necessário e universal sobre algo que, paradoxalmente, sempre pode ser de outro modo. O enredamento entre vida e história parece ser, portanto, um obstáculo incontornável ao critério de cientificidade que Dilthey pretende reconhecer nas ciências do espírito.

Não por acaso, ele se depara com o problema do historismo e nos chama a atenção para "a luta entre as tendências da vida e sua meta científica" (DILTHEY, 1978: 160). Nas

\footnotetext{
${ }^{3}$ Aqui vale lembrar as preciosas observações de Hegel sobre a necessidade de que algum indivíduo assuma o encargo de "iniciador", para que a "configuração incompleta de um Estado" possa adquirir uma unidade. Ora, isso mostra o poder de influência que um indivíduo pode ter sobre toda a comunidade, e vale tanto para a formação de um Estado quanto para as grandes revoluções políticas. Basta-nos lembrar de certas personalidades históricas, como, por exemplo, Napoleão Bonaparte. Cf. HEGEL, 2003: 258s.
} 
ciências do espírito, a contingência é um aspecto distintivo tanto do "objeto" (a vida) quanto do conhecimento que é elaborado em torno dele. Os próprios cientistas do espírito se encontram sob a influência de certas tendências da vida que, por sua vez, contrariam a meta científica de conhecê-la necessária e universalmente. Essas tendências agem silenciosamente sob a forma de dogmas e preconceitos relativos a uma época que, devido a essa relatividade, limitam a validade do conhecimento a um momento da história. É isso o que devemos ler nas seguintes palavras de Dilthey:

Como os historiadores, os economistas, os mestres do direito público, os que estudam a religião se encontram na vida, querem também influir sobre ela. Submetem os personagens históricos, os movimentos das massas e as diversas tendências ao seu próprio juízo, e este está condicionado por sua individualidade, pela nação a que pertencem, pela época em que vivem. [...] toda análise levada a cabo dos conceitos de uma geração passada nos mostra como nesses conceitos contêm elementos que procedem dos preconceitos da época. Mas já sabemos que toda ciência exige validez universal. Se há de haver, portanto, ciências do espírito, no sentido rigoroso da palavra 'ciência', terão de propor sua meta de um modo cada vez mais consciente e crítico. (DILTHEY, 1978: 160).

Por ainda adotar o critério de cientificidade das ciências naturais, Dilthey define a historicidade a partir de traços eminentemente negativos. A condição histórica das ciências do espírito é, sobretudo, um limite epistemológico para a elaboração de um conhecimento necessário e universal. Isso porque Dilthey também busca na vida o que as ciências naturais buscam no mundo físico: encontrar, sob a constante transformação do que se mostra à observação, algo estável, perene, em suma, cognoscível, ${ }^{4}$ a respeito do qual é possível formular leis.

Agora, então, a pergunta deve ser: podemos compreender a historicidade sem nos orientar por esse critério de cientificidade?

\subsection{A interpretação existencial de Heidegger.}

Embora fosse profundamente influenciado por Dilthey durante os estudos de juventude, Heidegger contorna o horizonte epistemológico de onde surge todo o projeto de fundamentação das ciências do espírito. Assim como a Dilthey, também devemos muito a

\footnotetext{
${ }^{4}$ Porque não parece ser possível conhecer o que muda a todo instante, desde Aristóteles, a constância de algo se tornou critério de cognoscibilidade, de maneira que aquilo que fosse eterno (aidion) ensejaria também a mais digna de todas as teorias, a "filosofia primeira". Cf. ARISTÓTELES, 2005: 269s.
} 
Heidegger o que atualmente compreendemos por historicidade. Mas isso não quer dizer que compartimos com tudo o que ele nos diz. Assim, passaremos propositalmente por cima da relação íntima que Heidegger estabelece entre a historicidade e os modos em que cada ser-aí ${ }^{5}$ pode assumir a própria existência, a fim de nos precaver de alguns problemas sobre os quais não poderemos tratar aqui. Concentraremo-nos apenas na correlação fundamental entre ser, tempo e historicidade.

Tudo o que Heidegger nos diz a respeito da historicidade parte de uma investigação acerca do sentido do ser em geral, cujo marco inicial é a obra Ser e tempo. Segundo Heidegger, embora não saibamos definir claramente o que significa 'ser', já nos movemos em uma compreensão prévia desse fenômeno tão corriqueiro. Podemos dar um exemplo bem simples. Compreendemos perfeitamente o que nos dizem em qualquer ocasião onde o verbo 'ser' é empregado: "Essa casa é branca", "Aquele sujeito é honesto", "As pinturas de Godá são belas” etc. Mas, se nos perguntassem: “o que significa ser, afinal?”, já não saberíamos responder satisfatoriamente.

Ora, esse mesmo problema surge com respeito ao tempo. Como já nos diz Santo Agostinho: “Quando dele falamos, compreendemos o que dizemos. Compreendemos também o que nos dizem quando dele nos falam. O que é, por conseguinte, o tempo? Se ninguém mo perguntar, eu sei; se o quiser explicar a quem fizer a pergunta, já não sei” (AGOSTINHO, 2000: 322). Isso mostra que certos fenômenos, embora sejam efetivos, só se mostram para nós de maneira obscura, de sorte que, inicialmente, não conseguimos defini-los com clareza. É o que ocorre com ser e tempo.

Mas o parentesco entre ser e tempo não se esgota aí. A fim de poder nos expressar com algum grau de clareza, tentaremos apresentar aqui uma compreensão provisória e geral acerca do que significa "ser". Tomemos como exemplo um caso em que demonstramos uma compreensão, por assim dizer, "mínima" a respeito do ser, quando simplesmente dizemos: "Isso é". Essa experiência nos mostra que a coisa visada aí se revelou ${ }^{6}$ para nós a partir daquilo que a determina enquanto tal e tal coisa. Deparamo-nos com algo e dizemos: "Isso é". Em geral, ser significa esse revelar-se de tudo aquilo com o qual podemos lidar, inclusive, nós mesmos.

\footnotetext{
${ }^{5}$ Ser-aí (em alemão, Dasein) é a palavra utilizada para designar o nosso modo específico de ser enquanto seres humanos, em contraste com o modo de ser dos animais, das plantas, das pedras etc.

${ }^{6}$ Ou ainda: tal coisa se mostrou, está disponível, para a compreensão.
} 
Mas importa mesmo é ressaltar a correlação essencial entre ser e tempo. Tudo o que é somente pode ser em alguma determinação temporal. Qualquer coisa necessariamente é, foi, será, vem sendo, tem sido etc. Aliás, enquanto "negação do tempo", até a própria atemporalidade provém de uma determinação temporal, visto que toda negação deve pressupor aquilo que nega. Por se tratar daquilo somente a partir do qual o ser se torna compreensível, o tempo é o que responde à pergunta de Heidegger acerca do sentido do ser (Cf. HEIDEGGER, 2002a: 54).

Ora, dentre todos os entes, somente nós perguntamos pelo sentido do ser. Nenhum animal, planta, pedra etc. pode fazer algo assim. Por conseguinte, somente em nós se realiza aquilo devido ao qual o ser se torna compreensível, a saber: o tempo! Para retomar o que já dissemos, só nos é possível reconhecer que as coisas são, porque aconteceu de nós existirmos no horizonte onde isso é possível, ou seja: no horizonte do tempo. Nós temporalizamos. Podemos dizer "Isso é", porque reconhecemos a coisa aí visada na sua permanência enquanto algo presente.

No entanto, o que Heidegger denomina temporalidade (Zeitlichkeit) não é simplesmente o fato de existirmos no horizonte do tempo. Antes, a temporalidade nomeia um "fenômeno uniforme" (einheitliche Phänomen) que, no dia-a-dia, é compreendido de modo desconexo como presente, passado e futuro (Cf. HEIDEGGER, 2002b: 120). Originariamente, não existimos em uma sucessão de instantes fragmentários que desaparecem um após outro à medida que passam. Tudo o que se revela na condição de algo presente, passado ou futuro, só pode ser reconhecido em um desses modos temporais, porque, na temporalidade de sua existência, o ser-aí já-veio-sendo-o-que-é-vindo-a-ser.

Restringimo-nos a fornecer apenas um panorama geral do que Heidegger descobriu acerca da relação fundamental entre ser e tempo. Nossa meta principal é mostrar como a historicidade se enraíza na temporalidade da existência do ser-aí. Algo só pode ser histórico para aquele a quem acontece existir temporalmente. Mais especificamente, um fato passado só pôde ter passado para aquele a quem acontece poder passar; um fato futuro só pode vir a acontecer para aquele que pode vir-a-ser e, como se diz, "permanecer na expectativa".

Há uma passagem sumamente importante no prólogo à conferência Tempo e ser que nos fornece o desenvolvimento necessário ao que já dissemos sobre o tempo: 
[...] então encontramos no ausentar, seja aquilo que foi, seja o futuro, uma maneira de presentar e de abordar (dirigir a) que, de modo algum, coincide com o presentar no sentido do presente imediato. De acordo com isto, tratase de observar: nem todo presentar é necessariamente presente; coisa estranha. Não obstante, encontramos tal presentar, a saber, a abordagem que nos alcança, também no presente. Também nele é-nos alcançado presentar. (HEIDEGGER, 1999: 260).

Aí toda a exposição se detém principalmente em dois modos temporais: passado e futuro. Vejamos, então. Quando dizemos "Isso é", fazemos a experiência de sermos abordados por algo que se dirige a nós em um presente imediato. É isso o que Heidegger chama "presentar": o fato de que algo nos aborda ao tornar-se presente diante de nós. Mas, quando se trata de algo passado ou futuro, isso também nos aborda, mas não na condição de algo imediatamente à vista. Trata-se de uma abordagem específica que Heidegger chama “ausentar". Daí o belo jogo de palavras: “nem todo presentar é necessariamente presente; coisa estranha”.

Essa estranheza só se desfaz quando notamos a diferença entre presentar e presente imediato. Esta mesa, por exemplo, me aborda em um presente imediato. Entretanto, aquilo que me aborda segundo o modo temporal passado se dirige a mim de maneira ausente, ou melhor, se faz presente - sem se fazer presente à vista. Eis a diferença! Apesar desse caráter, por assim dizer, "sorrateiro", a forma de abordagem do passado não deixa de surtir efeitos sobre nós. É isso o que nos interessa nessa passagem. Aqui temos em vista a maneira em que uma tradição histórica exerce a sua influência sobre nós, mesmo quando não lidamos diretamente com ela.

Em Verdade e método, Gadamer afirma que a tarefa da hermenêutica consiste em "fazer jus à historicidade da compreensão" (GADAMER, 2003: 354). Curiosamente, porém, ele parece ter negligenciado a importância que as interpretações de Heidegger sobre o tempo têm para a própria hermenêutica! Pois ainda não vimos Gadamer tratar seriamente essa questão. Em contrapartida, Heidegger não parece ter deixado de relacionar o tempo ou aos modos em que o ser-aí pode assumir a própria existência ${ }^{7}$ ou à relação com o ser enquanto ser. Até onde sabemos, não parece haver nas investigações de Heidegger uma interpretação do tempo desvinculada dessas duas abordagens. ${ }^{8}$

\footnotetext{
${ }^{7}$ Aqui, nos referimos aos dois possíveis modos de ser do ser-aí: a inautenticidade e a autenticidade, que ensejam a possibilidade de existir segundo uma temporalidade própria ou imprópria, respectivamente.

${ }^{8}$ Infelizmente, não podemos tratar aqui dos problemas daí decorrentes.
} 
Mas, graças a Heidegger esse fenômeno deixou de ser um fator epistemologicamente negativo para se enraizar na temporalidade da própria existência humana. Agora, ser histórico significa: existir de tal maneira, que aquilo que somos já envolve em si o que já viemos sendo e o que viremos-a-ser. Sorrateiramente, o que nos aborda no modo temporal passado se faz presente em nós sem se fazer claramente presente à vista. Assim, jogamos sem saber ao certo quais as regras do jogo. Eis porque este artigo se intitula justamente "o jogo da historicidade".

\section{O JOGO DA HISTORICIDADE.}

\subsection{O problema da independência do jogo.}

Originalmente, o fenômeno do jogo teve de oferecer uma resposta à pergunta acerca da "verdade da obra de arte", ao passo que aqui se trata de um problema distinto, talvez até bem mais abrangente. Porém, nas últimas páginas de Verdade e método, Gadamer ${ }^{9}$ mesmo sugere que o jogo é o modo em que nos relacionamos com a tradição e com a verdade. Mas não importa tanto se tais referências são insuficientes. A própria força daquilo que se tornará manifesto ao longo da nossa exposição poderá fazer ver se a historicidade é efetivamente um jogo.

A princípio, devemos enfatizar bem o propósito fundamental de Gadamer: libertar o jogo do "significado subjetivo que apresenta em Kant e Schiller" (GADAMER, 2003: 154). Não podemos perdê-lo de vista, pois toda a exposição se norteará a partir desse propósito. Por meio dele, Gadamer define a perspectiva sob a qual visa o fenômeno do jogo, qual seja, negar essa tendência para determinar o jogo a partir de fatores subjetivos. A essência do jogo, portanto, não está nem no comportamento nem no estado de ânimo nem na liberdade dos sujeitos que participam do jogo.

É em virtude dessa perspectiva, pois, que o jogo revela a Gadamer algumas determinações essenciais. A primeira delas consiste em que o jogo em si mesmo detém "uma natureza própria", "independente da consciência daqueles que jogam” (Ibid.: 155). Daí: "o sujeito do jogo não são os jogadores. Ele apenas ganha representação através dos que jogam o

\footnotetext{
${ }^{9}$ Basta-nos prestar atenção às últimas palavras de Gadamer em Verdade e método, onde nos diz, por exemplo: "o que nos vem ao encontro na experiência do belo e na compreensão do sentido da tradição tem realmente algo da verdade do jogo"; ou ainda: "a melhor maneira de determinar o que significa a verdade será, também aqui, recorrer ao conceito de jogo". Cf. Ibid.: 630-631. Além disso, o prof. Marco Casanova também procura mostrar em um artigo que toda a experiência da compreensão se resume a um jogo. (Cf. CASANOVA, 2008).
} 
jogo" (loc. cit.). Já vale notar que aqui, nessa independência do jogo, nasce o problema do qual trataremos adiante.

Para tais determinações, Gadamer encontra um fundamento fenomenológico nas metáforas da palavra 'jogo', que realçam, segundo ele, o seu "significado originário e próprio" (Ibid:: 156). O que há de comum em: jogo das luzes, jogo das ondas, jogo das forças, jogo das moscas, jogos das palavras e assim por diante? Ora, todas essas metáforas designam em comum "um movimento de vaivém" que não se fixa em nenhum alvo onde possa se concluir; um movimento "em constante repetição" onde não importa quem o execute moscas, ondas, palavras etc.; um movimento que, para se realizar, não requer nenhum sujeito específico. De maneira geral, portanto, “o jogo é a realização do movimento como tal” (Ibid.: 156). Sua determinação mais originária se encontra naquilo que acontece entre aqueles que perfazem o jogo, ou seja, "na forma medial" (Ibid.: 157).

Aqui, devemos explicitar uma conseqüência importante para os desdobramentos posteriores da nossa investigação. Quando se propõe a desvencilhar o jogo daquilo que acontece na consciência do jogador, Gadamer não visa qualquer forma de consciência, mas sim a consciência humana. Isso se torna mais claro quando ele busca dissolver a distinção entre uso próprio e metafórico da palavra 'jogo'. O emprego de uma palavra é considerado metáfora quando transpõe e amplia o campo de aplicação em que essa palavra vinha sendo empregada e que lhe conferiu um "significado próprio". Assim, “jogo das moscas" somente é considerado uma metáfora devido a uma tradição que sempre considerou o jogo uma atividade exclusivamente humana.

Portanto, Gadamer se contrapõe implicitamente a essa concepção antropológica do fenômeno do jogo, o que parece se evidenciar nessa passagem:

Do fato de o modo de ser do jogo encontrar-se tão próximo da forma de movimento da natureza, podemos extrair uma importante conclusão metodológica. É claro que não podemos dizer que os animais também jogam e que a água e a luz só "jogam" em sentido figurado. Antes, deveríamos dizer que também o homem joga. Também o seu jogar é um processo natural [...] Assim, nesse âmbito já não faz sentido distinguir entre uso próprio e metafórico. (GADAMER, 2003: 158, grifos nossos).

Notem bem. Aparentemente, Gadamer apenas diz que o ser humano não detém nenhum privilégio sobre a possibilidade de jogar, mas é apenas um dentre muitos outros que podem jogar. Todavia, essa crítica à concepção antropológica do jogo esconde um teor bem mais incisivo. Se não há razão para considerar que o ser humano confere ao jogo um 
significado próprio, do qual derivariam aqueles empregos metafóricos, também não há razão para atribuir esse encargo a nenhuma outra coisa. Assim, o fenômeno do jogo passa a revelar uma generalidade tal, que leva Gadamer a defender a sua independência em relação à consciência humana!

Mas aonde queremos chegar, afinal? Ora, se prestarmos atenção, o que Gadamer nos diz implica a independência do jogo em relação à própria natureza dos jogadores, de quaisquer jogadores, não importa se forem humanos, cores, moscas etc. Basta-nos deixar que alguns desdobramentos da própria exposição de Gadamer falem por si mesmos:

Em princípio, percebemos aqui o primado do jogo faca à consciência do jogador [grifo do autor], e se partirmos de fato do sentido medial do jogo [...] fica claro que o jogo representa uma ordem na qual o vaivém do movimento do jogo se produz como que por si mesmo [grifo nosso]. [...] A estrutura ordenadora do jogo faz com que o jogador se abandone a si mesmo, dispensando-o assim da tarefa da iniciativa [...] É o que aparece também no impulso espontâneo para a repetição, que surge no jogador e no contínuo renovar-se do jogo [...]. (Ibid.: 158).

Logo adiante, nos deparamos com uma conclusão, para nós, profundamente problemática, porém, fatal e bem coerente com o que Gadamer já disse:

Dessa análise destaca-se um traço comum no modo como a natureza do jogo se reflete no comportamento lúdico: Todo jogar é um ser-jogado. ${ }^{10} \mathrm{O}$ atrativo do jogo, a fascinação que exerce, reside justamente no fato de que o jogo se assenhora do jogador. [...] Justamente essas experiências em que há apenas um único jogador demonstram que o verdadeiro sujeito do jogo não é o jogador mas o próprio jogo. É o jogo que mantém o jogador a caminho, que o enreda no jogo e que o mantém nele. (Ibid.: 160, grifos do autor).

Vejamos agora como as proposições de Gadamer decorrem umas das outras. Tudo o que ele nos revela parte sempre de um único ponto: a "forma medial", o movimento de vaivém. É impossível que alguém queira jogar contando só consigo mesmo, pois assim não se estabeleceria nenhuma relação medial. Mas, para haver jogo, também não são necessários dois jogadores, mas apenas outra coisa com que se possa jogar e que, por si mesma, "responda com um contralance ao lance do jogador". Por isso, Gadamer" ${ }^{11}$ traz à tona os jogos feitos para apenas um jogador.

\footnotetext{
${ }^{10}$ No original: Alles Spielen ist ein Gespieltwerden. Cf. GADAMER, 1990: 112.

${ }^{11}$ Em outra passagem, ele toma como exemplo um gato que brinca com um novelo de lã. Cf. GADAMER, 2003: 159. É o que podemos ver também em outro exemplo, bem comum no futebol, quando gritamos: "Apanhou da bola!", para caçoar um jogador que pisa e tropeça na bola ao tentar um drible malsucedido.
} 
Ora, o que motiva Gadamer a dizer que o jogador, no fundo, é jogado pelo jogo é justamente essa sujeição aos contralances possíveis daquilo com que ele joga. Segundo ele, isso comprova que o agente do jogo não é a consciência do jogador. Logo, o "verdadeiro sujeito do jogo não é o jogador”, mas sim “o próprio jogo”. Disso seguem outras implicações. "O jogo se assenhora do jogador" e o leva a "abandonar a si mesmo" em favor do movimento do jogo que consiste naquele vaivém, ou ainda, no "impulso espontâneo para a repetição".

Agora, se retomarmos o tema da nossa investigação, então veremos quão problemático tudo isso deve ser. Se essa for mesmo a essência do jogo, a história deveria ter uma natureza própria, independente daqueles que dela fazem parte. Mas não só. Seríamos jogados pela história - "o verdadeiro sujeito do jogo" - que imporia a todos um "impulso espontâneo para a repetição". Enfim, segundo Gadamer, o fenômeno do jogo deveria revelar o caráter determinista e também relativista da história. Pois, se ela predeterminasse por si mesma os nossos movimentos, tudo o que fazemos seria relativo aos ditames do período histórico em que vivemos.

Mas a dialética de Hegel nos ensina que qualquer pensamento já traz consigo as condições da sua própria superação. Isso não invalida e esvazia por completo tudo aquilo que tal pensamento pôde nos mostrar; apenas exige que o elevemos mais uma vez ao nível do conceito para aí preservar aquilo mesmo que o inquietou e o motivou. Seria um erro crasso desconsiderar o que Gadamer, a partir do jogo, nos revela sobre a historicidade. Não podemos deixar de reconhecer que um traço marcante do jogo da história é a sua tendência para nos fazer repetir aquilo que veio vigorando desde muito tempo. Ora, em latim, 'tradição' significa "transmissão" e, ao transmitir algo, esperamos que isso permaneça vigente naqueles aos quais o legamos.

Entretanto, há a possibilidade de realizar um contralance ao que Gadamer nos legou. Prestemos atenção ao que ele nos diz nessa passagem:

[...] os jogos possuem um espírito próprio e pessoal. Isso tampouco se refere ao humor ou ao estado psíquico daqueles que jogam o jogo. Ao contrário, essa diversidade do estado de ânimo ao se jogar diferentes jogos ou ao sentir prazer em tais jogos é consequencia e não causa da diversidade dos próprios jogos. Os próprios jogos distinguem-se entre si por seu espírito. A única base para isso está no fato de eles prefigurarem e ordenarem cada vez diferente o vaivém do movimento do jogo. O que constitui a essência do jogo são as regras e disposições que prescrevem o preenchimento do espaço lúdico. (Ibid.: 160). 
Sim, o que promove a mudança de humor do jogador ao passar de um jogo a outro é a própria natureza do "espaço lúdico" aberto em cada jogo, mas não a disposição do jogador para alterar o próprio ânimo. Isso nós não questionamos. Mas, se a essência do jogo se encontra no movimento de vaivém entre os jogadores, mas não neles enquanto jogadores com certa natureza - se assim for, como um jogo pode se diversificar de outro? Como o jogo das moscas, por exemplo, pode se diferenciar do jogo das cores, uma vez que nem as moscas nem as cores participam da essência do jogo, que reside exclusivamente na "forma medial" comum a ambos os jogos?

Ora, se considerássemos seriamente o que nos diz, a resposta de Gadamer seria absurda. Se o que caracteriza um jogo fosse apenas o que ocorre entre os jogadores, deveria ser possível que essa relação medial se instaure por si mesma sem que os próprios jogadores existam! Assim, o movimento conjunto que fosse próprio a cada jogo e que lhe conferisse um traço distintivo em comparação com os outros jogos - esse movimento poderia preexistir aos jogadores, para somente depois submetê-los a si, a fim de instaurar concretamente a diversidade de jogos. Se formos coerentes com o que Gadamer ${ }^{12}$ nos diz, essa deveria ser a resposta dele, que nos parece um total disparate. E é com essa inquietação que passamos à próxima seção.

\subsection{A transformação: uma tarefa do jogo da historicidade.}

A nossa resposta para o problema com que concluímos a seção anterior deve sim considerar o quinhão de verdade do que Gadamer nos diz. De fato, a "forma medial" do jogo não depende do que ocorre subjetivamente nos jogadores. Porém, isso não significa que ela aconteça "como que por si mesma"! Pode haver ainda, eis toda a questão, a possibilidade de que o jogo dependa dos jogadores de outra maneira. Como ainda mostraremos, a natureza dos jogadores - e não a consciência subjetiva deles! - é determinante para a instauração do movimento do jogo.

Na última passagem citada, Gadamer diz: "O que constitui a essência do jogo são as regras e disposições que prescrevem o preenchimento do espaço lúdico". Decerto, o movimento de vaivém do jogo consiste em uma ordenação que abre um espaço lúdico e que prefigura o que pode acontecer nele. Assim, os limites de um jogo são estabelecidos no

\footnotetext{
${ }^{12}$ Vale ressaltar aqui as palavras de Gadamer já citadas anteriormente: “[...] o vaivém do movimento do jogo se produz como que por si mesmo [...]”. Cf. Ibid.: 158.
} 
interior desse espaço, e não devido a alguma restrição externa. Segundo Gadamer, essa é a "única base" para que um jogo se diferencie dos outros e se diversifique durante a realização do seu próprio movimento.

Entretanto, ainda que possa prescindir do que ocorre subjetivamente com o jogador, o jogo não pode prescindir da natureza mesma dos jogadores; não pode ser indiferente para a ordenação que abre e prefigura o espaço lúdico que os jogadores sejam moscas, ondas, cores, humanos etc. A "forma medial" do jogo somente pode ser o que é devido àquilo que os jogadores podem fazer uns com os outros. Ora, nenhum jogo pode prefigurar um espaço lúdico que exija dos jogadores a execução de lances que estejam além das suas possibilidades factíveis! É impossível organizar, por exemplo, um jogo de futebol com dois times formados por cães sem realizar qualquer adaptação nas regras tradicionais do futebol. - O jogo depende sim de quem joga.

Tudo o que dissemos coere plenamente com o propósito de livrar o jogo em si mesmo do que acontece subjetivamente com os jogadores. Mas Gadamer negligencia uma distinção importante. Temos diante de nós um fenômeno com dois aspectos distintos - porém, correlacionados. Por um lado, a natureza do jogo em si mesmo e, por outro lado, a natureza dos jogadores. E o primeiro não pode ser determinado sem o segundo. A natureza do jogo nos revela o que determina o movimento conjunto; a natureza dos jogadores, o que determina cada um como tal. Ora, o movimento conjunto depende do que cada um pode fazer consigo e com os outros.

Quanto ao jogo humano particularmente, seguiremos apenas os apontamentos de Gadamer que podem contribuir com a nossa investigação. Segundo ele, é característico do jogo humano jogar alguma coisa (Cf. Ibid.: 161s). Mas o que quer dizer "jogar algo"? Desempenhar a tarefa que o jogo designa e representá-la para os outros com os quais se joga. Mas em que consiste essa tarefa? Decerto, isso dependerá da natureza particular do jogo. No futebol, por exemplo, cabe ao lateral ocupar os flancos do campo, de modo que, no campo de ataque, deve cruzar a bola para os atacantes e, no campo de defesa, deve auxiliar os zagueiros na marcação desse setor.

Pois bem. Propomo-nos a tratar aqui do jogo da historicidade. Assim, a pergunta passa a ser: que tarefa nos designa esse jogo? Não por acaso, começamos este artigo com algumas considerações sumárias sobre o caráter essencialmente inter-humano e histórico da 
linguagem. Ninguém pode instituir linguagem recorrendo exclusivamente a si mesmo, ${ }^{13}$ sem contar com a linguagem já estabelecida em conjunto pelos outros. Assim, a fala é necessariamente um ato de coexistência. Então, isso quer dizer que ao falar desempenhamos uma tarefa? Qual?

Ora, a própria palavra 'tradição' responde a essa pergunta. Cabe-nos transmitir adiante o legado que os outros nos passam quando nos ensinam a falar. Essa é a tarefa que devemos desempenhar inicialmente para que possamos tornar concreta a simples possibilidade de falar. Aprender a falar implica aprender a pensar tal como uma longa tradição já vinha pensando; implica aprender a compreender as coisas, a si mesmo e os outros tal como já vinham sendo compreendidos. Existir historicamente é participar de uma ordem que abre e prefigura um espaço de movimentação. Enfim, essa é a primeira característica do jogo da historicidade.

Então só nos resta repetir o que é transmitido no vaivém do jogo da tradição? Já que dependemos dos outros para fazer aquilo que nos cabe enquanto humanos: existir na linguagem, então, de fato é necessário nos submeter à tendência para repetir a tradição. Notem: trata-se apenas de uma tendência. É justamente aí que a interpretação de Gadamer revela problemas sérios. Se o jogo histórico independesse da nossa natureza, deveríamos sucumbir a uma interpretação determinista e relativista da historicidade; deveríamos sucumbir à condição de "sermos jogados" pelo jogo da história, de maneira que estaríamos condenados a repetir o que a tradição já vinha transmitindo. Ora, nesse caso, já não está mais em questão uma mera tendência.

Realmente, até fizeram várias críticas contra a hermenêutica de Gadamer que denunciavam um problema similar. Talvez com o propósito de respondê-las, em um artigo intitulado Até que ponto a linguagem prescreve o pensamento Gadamer escreve:

O fato de nos movermos no mundo da linguagem, de estarmos inseridos em nosso mundo através da experiência pré-formada pela linguagem não restringe nossa possibilidade crítica. Ao contrário. Abre-se para nós a possibilidade de ultrapassar nossas convenções e todas as nossas experiências pré-esquematizadas, dialogando com outras pessoas, pessoas que pensam diferente, aceitando um novo exame crítico e novas experiências. (GADAMER, 2004: 239, grifo nosso).

\footnotetext{
${ }^{13}$ Quanto a essa questão, remetemos aos notórios argumentos de Wittgenstein contra a possibilidade de alguém instituir uma linguagem que só ele pode compreender. (Cf. Wittgenstein, 2000).
} 
Por si, essa passagem não resolve nada, pois não dirimi a sua incoerência com os problemas já mencionados. Ela apenas mostra que somos impelidos a manter com Gadamer uma relação ambígua. Às vezes, temos de concordar com ele para, em outras ocasiões, dele discordar. Sim, "o mundo da linguagem" possibilita a convivência com pessoas que "pensam diferente". E umas podem proporcionar a outras um "exame crítico" do que nelas está préesquematizado. Ora, se assim for, o espaço de jogo jamais pode estar totalmente prefigurado.

De fato! Se, por um lado, a linguagem é essencialmente um fenômeno interhumano, por outro lado, porém, ela não pode ser instituída exclusivamente a partir do que acontece entre os seres humanos. A linguagem também deve contar com a iniciativa de cada um deles em particular. Ninguém pode fazer com que alguém fale. É necessário que cada um tome a iniciativa de se apropriar disso sobre o qual ele pode falar! Por isso, é fundamental considerar a diferença entre o movimento medial do jogo e aquilo que cada jogador pode fazer por natureza.

Assim, concordamos com o que Gadamer diz no artigo Semântica $e$ hermenêutica:

O que constitui a vida da linguagem é o fato de jamais podermos nos afastar
completamente das convenções da linguagem. Aquele que fala uma língua
particular, que ninguém entende, simplesmente não fala. Por outro lado,
quem só fala uma língua inteiramente assolada pela convencionalidade, tanto
na escolha dos vocábulos quanto na sintaxe e no estilo, perde o poder de
interpelação e de evocação, apenas alcançável pela individualização do
acervo e dos recursos da linguagem. (Ibid.: 207-208).

Portanto, uma linguagem baseada somente no que os outros estabeleceram seria tão impossível quanto uma linguagem exclusivamente pessoal. Se a possibilidade de falar se baseasse estritamente em convenções preestabelecidas, não passaríamos de autômatos que se restringem a aplicar mecanicamente regras gramaticais ao léxico de uma língua completamente aistórica. Aí, sim, estaríamos condenados a simplesmente repetir a tradição.

Ao contrário, para participar de uma convenção, cada um de nós deve consentir nesse acordo. Tal consentimento só acontece porque podemos fazer nós mesmos certas experiências por meio daquilo que se estabeleceu por convenção. É necessário que reconheçamos a nós mesmos naquilo que é comum, pois só assim podemos realizar projetos que nos dizem respeito. Em uma palavra, se a possibilidade de falar dependesse somente daquilo que já foi preestabelecido, o movimento conjunto de uma tradição sequer seria 
possível. Ele depende de que nós mesmos façamos as experiências que ele nos transmite, o que ninguém mais pode fazer por nós.

É isso o que ganha voz na hermenêutica de Schleiermacher por meio da proposição: individuum est ineffabile, e mais tarde ressoa nas investigações de Dilthey. Porém, na ontologia de Heidegger, isso se converte na possibilidade de por entre parênteses toda a tradição precedente em virtude de uma experiência existencial de singularização extrema. Agora, isso se manifesta para nós como a necessidade de que aquilo que caracteriza o movimento de uma tradição passe pela mediação da experiência irredutivelmente singular de cada um.

Enfim, pretendemos evitar dois extremos. Por um lado, absolutizar a singularidade de cada um a ponto de fazer dela um meio para nos livrar totalmente dos influxos sorrateiros da tradição. Por outro lado, considerá-la nula perante a nossa tendência para repetir o que a história nos transmite. Por isso, a transformação também deve ser uma tarefa do jogo da historicidade. Sim, é uma condição necessária retomar a tradição para que possamos fazer o que nos cabe: falar. Mas também não podemos estar perpetuamente acorrentados a isso que, apenas inicialmente, nos foi imposto. Sempre o transformamos a partir do que temos de singular.

Todavia, essa transformação não se manifesta apenas como uma determinação puramente ontológica do ser humano. $\mathrm{O}$ fato de cada um ser singular e não poder transferir o encargo da sua própria existência a outro - esse fato tem uma determinação eminentemente prática. Cada nexo histórico só se pode ser estabelecido mediante a experiência efetiva e singular daqueles que fazem parte desse nexo. É por isso que o movimento do jogo da historicidade não pode ser completamente prefigurado. A transformação ${ }^{14}$ se realiza a cada instante em cada um, em um exercício infinito do qual podemos nos apropriar sem jamais, porém, chegar a um termo.

Enfim, a realidade última da historicidade humana é o contralance aos lances do jogo.

\footnotetext{
${ }^{14}$ Por transformação, não compreendemos aqui "revoluções políticas" ou mudanças explícitas, visíveis para qualquer um, que trouxessem melhor qualidade de vida a camadas sociais desfavorecidas economicamente. Transformação pode se referir também a meras reformulações que não promovem nenhuma mudança mais radical na ordem vigente de uma sociedade. Ainda não estamos em condições de tratar desses assuntos, pois eles demandam reflexões mais detidas acerca do que define em geral a transformação no jogo da historicidade. Este artigo é apenas um ensaio, um primeiro esforço nesse sentido.
} 


\section{REFERÊNCIAS BIBLIOGRÁFICAS.}

ABBAGNANO, Nicola. Dicionário de filosofia. 4. ed. São Paulo: Martins Fontes, 2000.

AGOSTINHO, Santo. Confissões. São Paulo: Nova Cultural, 2000. (Coleção Os Pensadores).

ARISTÓTELES. Metafísica. 2. ed. São Paulo: Edições Loyola, 2005.

BACK, Rainri. Nos rastros da situação hermenêutica. 2009. 124f. Dissertação (Mestrado em filosofia). Instituto de Ciências Humanas, Universidade de Brasília, Brasília, 2009.

CASANOVA, Marco A. A compreensão em jogo ou o jogo da compreensão. Mente, Cérebro \& Filosofia: Ricoeur e Gadamer: presença do outro e interpretação, São Paulo: Duetto, n. 11, p. 59-65, ago, 2008.

DILTHEY, Wilhelm. El mundo histórico. 1. reim. México: Fondo de Cultura Económica, 1978. . Teoria das concepções do mundo. Lisboa: Edições 70, 1992.

Lisboa: Edições 70, 2002.

Psicologia e compreensão: idéias para uma psicologia descritiva e analítica.

GADAMER, Hans-Georg. Wahrheit und Methode: Grundzüge einer philosophischen Hermeneutik. In: Gesammelte Werke. Bd. I. 6. Aufl. Tübingen: JCB Mohr, 1990.

. Verdade e método I: traços fundamentais de uma hermenêutica filosófica. 5. ed. rev. Rio de Janeiro: Vozes; São Paulo: Editora Universitária São Francisco, 2003.

Verdade e método II: complementos e índice. 2. ed. Rio de Janeiro: Vozes; São Paulo: Editora Universitária São Francisco, 2004.

HEGEL, Georg F. W. Princípios da filosofia do direito. São Paulo: Martins Fontes, 2003.

HEIDEGGER, Martin. Heidegger: conferências e escritos filosóficos. São Paulo: Nova Cultural, 1999. (Coleção Os Pensadores). . Sein und Zeit. 18. Aufl. Tübingen: Max Niemeyer, 2001.

São Francisco, 2002a.

Ser e tempo. v. I. 12. ed. Rio de Janeiro: Vozes; São Paulo: Editora Universitária . Ser e tempo. v. II. 10. ed. Rio de Janeiro: Vozes; São Paulo: Editora Universitária São Francisco, 2002b.

SCHLEIERMACHER, Friedrich D. E. Hermenêutica: arte e técnica da interpretação. 2. ed. Rio de Janeiro: Vozes, 2000.

WITTGENSTEIN, Ludwig. Investigações filosóficas. São Paulo: Nova Cultural, 2000. 